\title{
Organized leisure-time sport participation and academic achievement in preadolescents
}

\author{
ELVAR SMARI SÆVARSSON ${ }^{1}$, ERLA SVANSDOTTIR ${ }^{1}$, THORARINN SVEINSSON², \\ TINNA LAUFEY ASGEIRSDOTTIR ${ }^{3}$, SIGURBJORN ARNI ARNGRIMSSON ${ }^{1}$ \\ \& ERLINGUR JOHANNSSON ${ }^{1,4}$
}

${ }^{1}$ Centre for Health and Sport Sciences, School of Education, University of Iceland, Reykjavik, Iceland, ${ }^{2}$ Research Centre for Movements Sciences, University of Iceland, Reykjavik, Iceland, ${ }^{3}$ Faculty of Economics, University of Iceland, Reykjavik, Iceland, and ${ }^{4}$ Department of Sport and Physical Activity, Bergen University College, Bergen, Norway

\begin{abstract}
Aims: The aims of this study were to study the correlation between lifestyle-related factors, such as organized leisuretime sport participation (OLSP), cardiorespiratory fitness, and adiposity, and academic achievement among preadolescents. Methods: A cross-sectional study involving 248 nine-year-old school children was carried out. OLSP was self-reported with parental assistance, categorized as $\leq 1 \times$ a week, $2-3 \times$ a week, and $\geq 4 \times$ times a week or more. Academic achievement was estimated with results from standardized test scores in Icelandic and math. Cardiorespiratory fitness was estimated using a maximal cycle ergometer test. The sum of four skinfolds was used to estimate adiposity. Results: Tests of between-subjects effect indicated that OLSP significantly correlated with achievement in math only $(\mathrm{F}(2,235)=3.81, p=0.024)$. Further analysis showed that the two less active groups had significantly lower scores in math compared to the most active group with OLSP $\geq 4 \times$ times a week or more $(2-3 \times$ times a week, unstandardized coefficient $(b)=-4.08,95 \%$ confidence interval (CI) $[-7.09,-1.07] ; \leq 1 \times$ a week, $b=-3.84,95 \%$ CI $[-7.59,-0.08]$ ), independent of sex, age, maturity level (age to/from peak height velocity), family structure, and parental education. Neither cardiorespiratory fitness nor adiposity significantly correlated with academic achievements. Conclusions: The study's result indicates that frequent (four times per week or more often) sport participation is not harmful but may be beneficial to learning. However, further intervention-based study of this topic is needed to determine if this relationship is causal.
\end{abstract}

Key Words: Physical activity, children, exercise, academic performance, preadolescent, learning

\section{Introduction}

It is well established that physical activity is associated with multiple health benefits in children and adolescents, but evidence suggests that physical activity is also associated with academic achievement $[1,2]$, an important influential factor for the future educational attainment and health of individuals $[3,4]$. One aspect of physical activity is sport participation [5], which is offered to children and adolescents in school environments or as an organized leisure-time sport participation (OLSP) by sport clubs in most western countries. A positive correlation between sport participation and academic achievement has been established in studies primarily involving adolescents participating in school sports [6,7]. However, school sports have been argued to enhance school identification which may promote academic achievement [8], and requirements that athletes maintain minimum grades to be

Correspondence: Erlingur Jóhannsson, Centre for Health and Sport Sciences, School of Education, University of Iceland, 840 Laugarvatn, Iceland. E-mail: erljo@hi.is

Date received 14 fune 2016; reviewed 6 March 2017; accepted 22 March 2017

(C) Author(s) 2017

Reprints and permissions: sagepub.co.uk/journalsPermissions.nav DOI: $10.1177 / 1403494817705560$

journals.sagepub.com/home/sjp 
eligible to participate may cause grade inflation [9]. Fewer studies have investigated the association between sport club OLSP and academic achievement, but adolescent OLSP has been shown to correlate with future educational attainment and cognitive performance $[10,11]$. In the only other known study involving OLSP in pre-adolescents, Haapala et al. [12] reported a positive association between engagement in OLSP of any kind and achievement in math among six-year-old children.

Cardiorespiratory fitness and adiposity are considered important health markers in children and adolescents $[13,14]$. The association of cardiorespiratory fitness $[15,16]$ and adiposity $[17,18]$ with academic achievement is contradictory and inconclusive. This discrepancy might be explained by the different methods used to measure and express fitness, and the lack of adjustments for confounding factors in some studies.

Given the importance of academic achievement, and resulting educational attainment, for future health and well-being, it is imperative to understand its determinants. The positive influence OLSP may have on academic achievement constitutes an argument for increasing the availability of sports for children to participate in without jeopardizing school learning. The aims of this study were, therefore, to: a) further the findings of Haapala et al. [12] by exploring if there is a dose-response present in the relationship between OLSP and academic achievement among preadolescents; and $\mathrm{b}$ ) explore the correlation of adiposity and cardiorespiratory fitness with academic achievement among preadolescents.

We hypothesized that: a) based on the physical activity component of OLSP $[19,20]$, it would positively correlate with academic achievement; b) adiposity would not correlate with academic achievement since our study included an estimate of socio-economic status (parental education) which has shown to eliminate the correlation when adjusted for [21]; and c) cardiorespiratory fitness would not correlate with academic achievement.

\section{Methods}

\section{Participants}

The study population stems from two different epidemiological studies conducted in Iceland involving nine-year-old children. The first study, "Lifestyle of 9- and 15-year-old Icelandic children" [22], included nationally representative data collected from September 2003 to January 2004 on children born in $1994(n=662$ invited to participate, $n=488$ accepted), and is a part of the European Youth Heart Study (EYHS) [23]. Half of the cohort was randomly selected and offered to participate in the cardiorespiratory fitness test. Participants in the study were approached in 2014, at age 20 years, by mail and phone and asked for their consent to add their academic achievement to the database. Of the 307 of those who consented to participate, 152 had a valid cardiorespiratory fitness test (heart rate $\geq 185 \mathrm{bpm}$ ). The second study, "Lifestyle of 7- and 9-year-olds: Intervention toward better health" [24], was an intervention study conducted in 2006-2008. It involved children born in 1999 ( $n=324$ invited to participate, $n=256$ accepted) from the nation's capital, Reykjavík. In the last phase of data collection (used in this study), conducted from late August to early December 2008, 172 had a valid cardiorespiratory fitness test. The total number of participants in the aforementioned studies with a valid cardiorespiratory fitness test was 324 , and 258 possessed all the information required for statistical analysis in the current study; that is, questionnaire information and a valid cardiorespiratory fitness test. The National Bioethics Committee in Iceland approved the study (VSNa2003060014/03-12/BH/-).

\section{Questionnaire}

With the assistance of their legal guardians, participants filled out a questionnaire assessing various health behaviours, which was based on the EYHS questionnaire. The legal guardians also completed a separate questionnaire on themselves, including educational level and income. The question concerning respondents' OLSP was as follows: "How often do you participate (practice or compete) in sports with a club?" The response options were: "Never" $(n=37)$; "Less than once a week" $(n=6)$; "Once a week" $(n=12)$; "2-3 times a week" $(n=129)$; " $4-5$ times a week" ( $n$ $=60)$; and "Almost every day" $(n=14)$. Due to the low response rate in some options and to equalize group sizes, responses where coded into three categories with "Once a week or less" as "inactive", 2-3 times a week as "active", and 4 times a week or more often as "very active".

\section{Academic achievements}

Grades from standardized tests in Icelandic and math in fourth grade, retrieved from The National Examination Institute, were used to assess academic achievement. These tests were developed by The National Examination Institute and are administered once a year in September to all students attending 4th, 7 th, and 10th grade in the country, to assess standing in Icelandic and math. The test in Icelandic estimates performance in reading, writing, and grammar and 
comprises multiple choice questions, reading comprehension, writing short stories, and correct use of words. The test in mathematics comprises multiple choice questions, word problems, sentence completion, operations, geometry, and numerical understanding $[25,26]$. The nationwide results were normalized with a mean of 30 , and a standard deviation of 10 . Total scores ranged from 0 to $60[25,26]$.

\section{Cardiorespiratory fitness and anthropometry}

Height $(\mathrm{cm})$ and weight $(\mathrm{kg})$ were measured to the nearest 0.1 using standard procedures allowing for the calculation of body mass index $\left(\mathrm{BMI} ; \mathrm{kg} / \mathrm{m}^{2}\right)$. Cardiorespiratory fitness was measured with a progressive and maximal cycle ergometer test using the study protocol from the EYHS [23]. The workload was pre-programmed on a computerized Monark 829E cycle ergometer (Monark Exercise $\mathrm{AB}$, Vansbro, Sweden) to increase every third minute until the subject reached exhaustion. Cardiorespiratory fitness was expressed with the commonly used ratio scaling (W/kg) to adjust for different body sizes. Mathematically, ratio scaling assumes a linear relationship between absolute values and body weight, with a y-intercept equal to zero. This assumption is, in fact, rarely satisfied in biological research [27]. Therefore, body size was also adjusted for using linear regression scaling [28], but since results were not affected by the cardiorespiratory fitness expression the more commonly used ratio scaling is displayed in the results. Adiposity was estimated as the sum of four skinfold sites: triceps, biceps, subscapular, and suprailiac.

\section{Covariates}

Maturity level was estimated using newly developed sex-specific equations, which estimate years from/to peak height velocity (i.e. maturity offset $=-7.99994+$ $(0.0036124 \times$ age $\times$ height $)$ for boys and $-7.709133+$ $(0.0042232 \times$ age $\times$ height $)$ for girls [29]. Maturity level has been considered to be a proxy for neuromuscular function, a size-independent factor associated with growth and maturation [30]. A large proportion of the Icelandic population is of Norse and Celtic origin and about $86 \%$ belonged to the Lutheran Church at baseline [31]. Because of this homogeneity, demographic factors such as race, ethnicity, and religion were considered irrelevant and not included in the analysis. Other factors, known to be confounders when studying the relationship between health behaviours and academic achievement [31], were used as covariates in this study. These included: a) level of parental education, used as a proxy for socio-economic status and consisted of a dichotomous variable ( 0 and 1 ) with 1 representing one or both parents with a university degree; $b$ ) family structure, assessed by the question "how is your current living arrangement?" with the response options, "living with both parents", "living with a single parent", "living with a parent and his/hers spouse", and "other arrangement"; c) sex; and d) age in months [32].

\section{Data analysis}

The data were analysed using SPSS 22.0 (IBM Corp., Armonk, NY, USA). All variables were inspected for normality, the sum of four skinfolds was reciprocally transformed, and cardiorespiratory fitness log-transformed to correct for skewness [33]. Therefore, all positive skinfold slopes (betas) are in reality negative, and vice versa for negative slopes. One-way analysis of variance (ANOVA; continuous variables) and Chi-square (categorical variables) were used to explore the differences on key variables between the study sample and the rest of the cohort (excluded). One-way ANOVA and analysis of covariance (ANCOVA) were used to analyse differences in academic achievement between OLSP groups. The Tukey post hoc test was administered to explore differences between OLSP groups on academic achievement in crude analysis. Levene's test was used to estimate homogeneity of variance. No interactions were found between the OLSP groups and the other independent variables. Effect size was estimated using Cohen's $d$ [34]. Statistical significance was accepted at $\alpha$ level of 0.05 .

\section{Results}

The study sample and those who did not meet the inclusion criteria significantly differed on only two variables. The study sample had a lower sum of skinfolds and higher cardiorespiratory fitness level than those excluded (see Table I). The two study cohorts did not differ significantly in academic achievement with 1994 cohort's average score in Icelandic being 31.69 ( \pm 9.95$)$ vs. 32.69 ( \pm 10.28) for the 1999 cohort $(p=0.427)$. In math, the 1994 cohort's average was $30.34( \pm 10.37)$ vs. 31.7 ( \pm $10.11)$ for the 1999 cohort $(p=0.275)$. The nationwide average score in the two academic subjects was $30.0( \pm 10)[25,26]$.

In crude analysis, the Tukey post hoc test revealed that the very active group, which participated in OLSP four times or more often a week, had significantly higher grades in math than the active group and the inactive group, $p=0.014,95 \%$ confidence interval (CI) [0.70, 7.85]; effect size 0.45 , and $p=0.042,95 \%$ CI [0.14, 9.97]; effect size 0.42 respectively (see Figure 1). 
Table I. Participants' descriptive data and the representativeness of the study sample.

\begin{tabular}{|c|c|c|c|c|c|c|}
\hline & \multicolumn{2}{|c|}{ All $(n=640)$} & \multicolumn{2}{|c|}{ Study sample $(n=258)$} & \multicolumn{2}{|c|}{ Excluded $(n=382)$} \\
\hline & $N$ & mean $\pm \mathrm{SD}$ & $N$ & mean $\pm S D$ & $N$ & mean $\pm S D$ \\
\hline Age (years) & 639 & $9.35 \pm 0.29$ & 258 & $9.36 \pm 0.29$ & 381 & $9.35 \pm 0.29$ \\
\hline Height (cm) & 562 & $138.0 \pm 6.05$ & 258 & $138.3 \pm 5.59$ & 304 & $137.6 \pm 6.41$ \\
\hline Weight (kg) & 562 & $33.46 \pm 6.89$ & 258 & $33.45 \pm 6.44$ & 304 & $33.48 \pm 7.26$ \\
\hline MO (years) & 561 & $-2.75 \pm 0.60$ & 258 & $-2.74 \pm 0.62$ & 303 & $-2.76 \pm 0.59$ \\
\hline rSkinfolds (mm) & 560 & $0.032 \pm 0.013$ & 257 & $0.033 \pm 0.013$ & 303 & $0.031 \pm 0.013^{\star}$ \\
\hline BMI & 561 & $17.47 \pm 2.66$ & 258 & $17.38 \pm 2.49$ & 303 & $17.54 \pm 2.79$ \\
\hline Icelandic & 594 & $31.46 \pm 9.85$ & 251 & $32.31 \pm 10.28$ & 343 & $30.83 \pm 9.48$ \\
\hline Math & 603 & $30.25 \pm 9.98$ & 250 & $31.18 \pm 10.40$ & 353 & $29.58 \pm 6.64$ \\
\hline Sex & 640 & $342(53.4 \%)$ 우 & 258 & $139(53.8 \%)$ 우 & 382 & $203(53.1 \%)$ ㅇ \\
\hline Overweight $^{\mathrm{b}}$ & 561 & $111(19.8 \%)$ & 258 & $49(19 \%)$ & 303 & $62(20.5 \%)$ \\
\hline Obese $^{b}$ & 561 & $26(4.6 \%)$ & 258 & $10(3.9 \%)$ & 303 & $16(5.3 \%)$ \\
\hline Parents' education & 475 & $250(47.4 \%)$ & 258 & $131(51.3 \%)$ & 217 & $119(54.4 \%)$ \\
\hline Family structure & 475 & $349(73.5 \%)$ & 258 & $197(73.5 \%)$ & 217 & $152(70.0 \%)$ \\
\hline Sport participation & 428 & $114(27.0 \%)$ & 258 & $75(29.1 \%)$ & 170 & $39(22.9 \%)$ \\
\hline $\mathrm{CRF}_{\log }$ & 324 & $1.05 \pm 0.23$ & 258 & $1.07 \pm 0.23$ & 66 & $0.96 \pm 0.21^{\star}$ \\
\hline
\end{tabular}

SD: standard deviation; MO: maturity offset; rSkinfolds: sum of four skinfolds reciprocally transformed; BMI: body mass index; Parents' education: one or both parents with a university degree; Family structure: living with both parents; $\mathrm{CRF}_{\log }$ : cardiorespiratory fitness logtransformed.

b Cole (2000) [51].

${ }^{\star} p>0.05$.

The ANCOVA analysis, with math as the dependent variable $(n=247)$, showed that the very active group had significantly higher grades than the other two less active groups (see Table II). Neither adiposity nor cardiorespiratory fitness correlated significantly with academic achievement. When grades in Icelandic were entered as the dependent variable instead of math $(n=248)$, no significant association between OLSP and academic achievement were observed. Neither adiposity nor cardiorespiratory fitness correlated with achievement in Icelandic (see Table III).

\section{Discussion}

The main finding of this study is that the very active group had significantly higher grades in math than the two less active groups, independent of age, sex, adiposity, family structure, parental education, cardiorespiratory fitness, and maturity level. Therefore, the current study furthers the findings of Haapala et al. [12] by establishing a threshold in the association between OLSP and achievements in math among preadolescents. Our hypothesis that OLSP would be associated with academic achievement is partly explained as OLSP was only associated with achievement in math but not in Icelandic. The finding of no correlation of adiposity and cardiorespiratory fitness with academic achievement is congruent with our hypothesis. Haapala et al. [12] reported that participation in any kind of OLSP in first grade was associated with better math skills in grades
$1-3$, but not with reading fluency or reading comprehension, compared with those who did not engage in such activities.

This study did not reveal a significant doseresponse relationship in the association between OLSP and academic achievement. Dose-response relationships have been reported among adolescents [7,35]. Fox et al. [7] reported a dose-response relationship between the number of sports teams that participated and academic achievement (grade point average) among high-school students but not among middle-school students. This indicates that the strength of the dose-response might be smaller in younger participants. However, our study reveals a frequency threshold where participation may start to affect math scores, indicating that certain OLSP frequency [36] or intensity [37] must be met in order for OLSP to affect academic achievement. Another possible explanation is that only the most dedicated participants in OLSP possess or acquire the skills, for example, self-discipline, necessary for affecting academic achievement.

In line with the findings of Haapala et al. [12], OLSP was significantly associated with achievement in math but not in language. Based on these results, the most probable explanation for the established association between achievement in math and OLSP is the physical activity component of OLSP $[19,20]$. Fox et al. [7] reported that the association of sport participation and physical activity with academic achievement could not be separated from one another in middle-school students, which supports these 


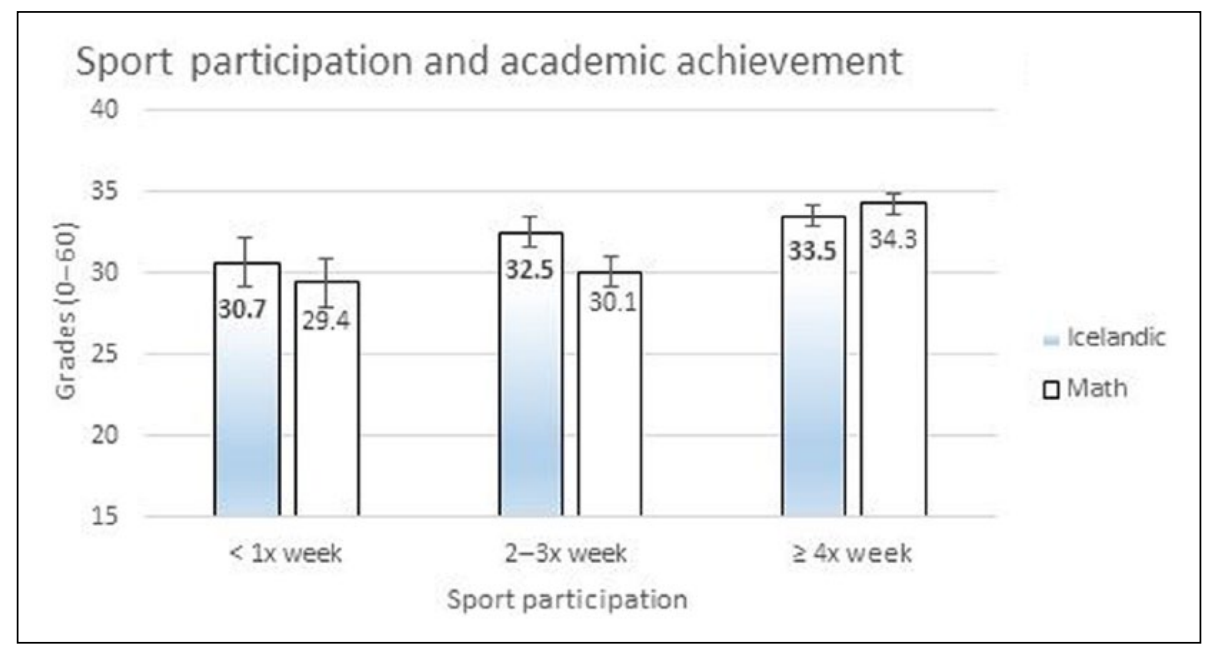

Figure 1. Mean comparison of sport participation frequency groups using one-way ANOVA with standard error bars. In math $[\mathrm{F}(2,244=$ $4.62, p=0.011], \geq 4 \times$ week vs. $2-3$ week, $p=0.014 \geq 4 \times$ week vs. $<1 \times$ week, $p=0.042$.

Table II. Results from ANCOVA analysis with achievement in math as the dependent variable.

\begin{tabular}{|c|c|c|c|c|c|}
\hline & $\mathrm{b}$ & Std. err. & Sig. & $95 \% \mathrm{CI}$ & PES \\
\hline Intercept & 47.79 & 35.69 & 0.182 & {$[-22.53,118.10]$} & 0.007 \\
\hline Parents' education & 4.30 & 1.53 & 0.001 & {$[1.69,6.95]$} & 0.043 \\
\hline Sport participation & & & 0.024 & & 0.031 \\
\hline$\leq 1 \times$ per week $(n=51)$ & -3.84 & 1.91 & 0.045 & {$[-7.59,-0.08]$} & 0.017 \\
\hline $2-3 \times$ per week $(n=125)$ & -4.08 & 1.53 & 0.008 & {$[-7.09,-1.07]$} & 0.029 \\
\hline$\geq 4 \times$ week $(n=71)$ & 0 & 0 & 0 & 0 & \\
\hline Maturity offset & 2.16 & 3.39 & 0.525 & {$[-4.51,8.83]$} & 0.002 \\
\hline rAdiposity & -48.02 & 61.25 & 0.434 & {$[-168.71,75,65]$} & 0.003 \\
\hline CRF $(\log )$ & 0.79 & 3.21 & 0.81 & {$[-5.53,7.12]$} & 0.000 \\
\hline
\end{tabular}

Adjusted for family structure, sex, age.

b: unstandardized coefficient; PES: partial eta squared; rAdiposity: reciprocally transformed sum of four skinfold; CRF: cardiorespiratory fitness; log: logistically transformed; Parents' education: $0=$ neither parent with a university degree, $1=$ one or both parents with a university degree; Maturity offset: years from peak height velocity.

Adj. $\mathrm{R}^{2}=0.06$

Table III. Results from ANCOVA analyses with achievement in Icelandic as the dependent variable.

\begin{tabular}{|c|c|c|c|c|c|}
\hline & $\mathrm{b}$ & Std. err. & Sig. & $95 \% \mathrm{CI}$ & PES \\
\hline Intercept & 12.89 & 33.89 & 0.704 & {$[-53.89,79.65]$} & 0.002 \\
\hline Parents' education & 5.50 & 1.27 & $<0.001$ & {$[2.99,8.01]$} & \\
\hline Sport participation & & & 0.750 & & 0.002 \\
\hline$\leq 1 \times$ per week $(n=52)$ & -1.33 & 1.81 & 0.462 & {$[-4.89,2,23]$} & 0.001 \\
\hline$-2-3 \times$ per week $(n=124)$ & -0.80 & 1.46 & 0.582 & {$[-3.68,2.07]$} & 0.001 \\
\hline$-\geq 4 \times$ week $(n=72)$ & 0 & 0 & 0 & 0 & \\
\hline Maturity offset & 2.33 & 3.19 & 0.466 & {$[-3.95,8.6]$} & 0.004 \\
\hline rAdiposity & -99.32 & 58.01 & 0.086 & {$[-214.21,14.36]$} & 0.010 \\
\hline CRF (log) & 0.19 & 3.08 & 0.95 & {$[-5.87,6.25]$} & 0.000 \\
\hline
\end{tabular}

Adjusted for family structure, sex, age.

b: unstandardized coefficient; PES: partial eta squared; rAdiposity: reciprocally transformed sum of four skinfold; CRF: cardiorespiratory fitness; log: logistically transformed; Parents' education: $0=$ neither parent with a university degree, $1=$ one or both parents with a university degree; Maturity offset: years from peak height velocity.

Adj. $\mathrm{R}^{2}=0.12$

speculations. The positive effect physical activity has on academic achievement may be explained by the effects it has on student's behaviour and cognitive abilities; for example, enhanced arousal, increased concentration, and lower rate of inappropriate talking [38]. Neurological and hormonal theories 
state that changes in brain structure, function, and neurotransmitter concentration occur in individuals who are more physically active, which again can enhance learning capabilities [39]. The stronger association of physical activity with math than language shown in this study is supported by results from previous studies [40,41].

Cardiorespiratory fitness was not associated with academic achievement in this study. In the literature, the correlations between cardiorespiratory fitness and academic achievement are inconclusive. This discrepancy might be explained with different ways to measure cardiorespiratory fitness. Studies using weight-bearing cardiorespiratory fitness tests (running or walking) [15,42] have shown positive associations, but studies using nonweight-bearing tests (cycle ergometer), which are relatively free from motor competence [16], have not. Motor control has been shown to associate with adolescent year's academic achievement [43], and Haapala et al. reported that poor motor performance was associated with worse academic skills among 6-8-year-olds [16].

Adiposity and academic achievement were not associated in our data. Findings in the literature concerning adiposity and academic achievement are inconclusive. An inverse correlation has been reported [44], while others have reported no correlation [17]. We can only speculate about the reasons for this discrepancy, but factors such as differences in adiposity estimation methods, age of participants, or statistical covariates may serve as plausible explanations. The negative association between obesity and academic achievement have been reported to disappear or be minimized when socio-economic status is adjusted for [21]. However, in our data, adiposity was still not correlated with academic achievement after parental education (a proxy for socio-academic status) was removed from the model (data not shown).

The real-life significance of this study's result can only be speculated; that is, whether the grade difference between activity groups is enough to affect future academic attainment and health. The reported effect sizes of 0.42 and 0.45 for the two groups with lower OLSP are close to the medium strength cut point of 0.5 [34]. Furthermore, effect sizes of 0.41-0.51 were reported to equal four months of learning gains compared to the control group in a randomized controlled trial exploring the association between physical activity and academic achievement [45].

This study possesses several strengths. Firstly, it included a high-quality estimate of academic achievement, using results from standardized tests which include all of the nation's fourth graders which are reviewed by an independent party at the National Examination Institute. Secondly, it employed a clearly defined aspect of physical activity or weekly frequency of OLSP. Finally, it included a high-quality laboratory-based cardiorespiratory fitness test. Limitations include that OLSP frequency was estimated via a questionnaire, and the validity of physical activity questionnaires has been questioned by some [46]. However, others have stated that questionnaires are the only currently feasible method to assess different types of physical activity and sedentary behaviour in population-based samples [47]. Information regarding the OLSP duration were not collected but the duration may possibly affect the associations between OLSP and academic achievement. Even though acute effects of physical activity on academic achievement have been reported [48], it may take months or years for other possible learning-enhancing factors (cooperation, discipline, obedience) to develop. Due to the cross-sectional study design, a definite causal relationship cannot be established. Future studies should collect data regarding what kind of sport students participated in since the association between sport participation and academic achievement may depend on the type of the sport [49]. Also, gathering information regarding motor control may also be important because of the possible confounding effect it may have on the association with physical activity and academic achievement $[16,50]$.

In conclusion, this study supports the hypothesis that in addition to the many health benefits of physical activity, it may also be associated with better academic achievement. Cardiorespiratory fitness and adiposity are not associated with academic achievements in 9-year-old Icelandic children. The results indicate that even though children participate in OLSP four times a week or more, it is not harmful to their academic achievement and may even benefit learning. Thus, communities may look to increase OLSP offerings independently and in cooperation with non-profit sport clubs. OLSP can be costly for families, so communities may consider assisting low-income families with OLSP for their children.

\section{Declaration of conflicting interests}

None declared.

\section{Funding}

This work was supported by the Icelandic Centre for Research (RANNIS), along with the Ministry of Education, Science and Culture, and the Icelandic Primary Health Care Research Fund.

\section{References}

[1] Rasberry CN, Lee SM, Robin L, et al. The association between school-based physical activity, including physical 
education, and academic performance: a systematic review of the literature. Prev Med 2011;52(1):S10-20.

[2] World Health Organization (WHO). Physical activity and young people, http://www.who.int/dietphysicalactivity/ factsheet_young_people/en/ (2015, accessed 29 December 2015).

[3] Kramer RA, Allen L and Gergen PJ. Health and social characteristics and children's cognitive functioning: results from a national cohort. Am $\mathcal{F}$ Public Health 1995;85(3):312-8.

[4] Lundetrae K and Gabrielsen E. Relationship between literacy skills and self-reported health in the Nordic countries. Scand $\mathcal{F}$ Public Health 2016; 44(8): 758-764.

[5] Caspersen CJ and Powell KE and Christenson GM. Physical activity, exercise, and physical fitness: definitions and distinctions for health-related research. Public Health Rep 1985;100(2):126-31.

[6] Trudeau F and Shephard RJ. Relationships of physical activity to brain health and the academic performance of schoolchildren. Am $\mathcal{F}$ of Lifestyle Med 2010;4(2):138-50.

[7] Fox CK, Barr-Anderson D, Neumark-Sztainer D, et al. Physical activity and sports team participation: associations with academic outcomes in middle school and high school students. F Sch Health 2010;80(1):31-7.

[8] Marsh H. The effects of participation in sport during the last two years of high school. Sociol Sport f 1993;10(1): $18-43$.

[9] Snyder EE and Spreitzer E. High school athletic participation as related to college attendance among black, Hispanic, and white males: a research note. Youth Soc 1990;21(3):390-8.

[10] Pfeifer C and Cornelißen T. The impact of participation in sports on educational attainment-new evidence from Germany. Econ Educ Rev 2010;29(1):94-103.

[11] Ruiz JR, Ortega FB, Castillo R, et al. Physical activity, fitness, weight status, and cognitive performance in adolescents. F Pediatr 2010;157(6):917-22, e1-5.

[12] Haapala EA, Poikkeus AM, Kukkonen-Harjula K, et al. Associations of physical activity and sedentary behavior with academic skills - a follow-up study among primary school children. PLoS One 2014;9(9):e107031.

[13] Ortega FB, Ruiz JR, Castillo MJ, et al. Physical fitness in childhood and adolescence: a powerful marker of health. Int f Obes 2008;32(1):1-11.

[14] Ruiz JR, Castro-Pinero J, Artero EG, et al. Predictive validity of health-related fitness in youth: a systematic review. $\mathrm{Br}$ F Sports Med 2009;43(12):909-23.

[15] Welk GJ, Jackson AW, Morrow JR, et al. The association of health-related fitness with indicators of academic performance in Texas schools. Res Q Exerc Sport 2010;81(3): S16-23.

[16] Haapala EA, Poikkeus AM, Tompuri T, et al. Associations of motor and cardiovascular performance with academic skills in children. Med Sci Sports Exerc 2014;46(5): 1016-24.

[17] LeBlanc MM, Martin CK, Han H, et al. Adiposity and physical activity are not related to academic achievement in school-aged children. $f$ Dev Behav Pediatr 2012;33(6): 486-94.

[18] Sardinha LB, Marques A, Martins S, et al. Fitness, fatness, and academic performance in seventh-grade elementary school students. BMC Pediatr 2014;14(1):176.

[19] Katzmarzyk P and Malina R. Contribution of organized sports participation to estimated daily energy expenditure in youth. Pediatr Exerc Sci 1998;10:378-386.

[20] Marques A, Ekelund U and Sardinha LB. Associations between organized sports participation and objectively measured physical activity, sedentary time and weight status in youth. F Sci Med Sport 2016;19(2):154-7.
[21] Torrijos-Nino C, Martinez-Vizcaino V, Pardo-Guijarro MJ, et al. Physical fitness, obesity, and academic achievement in schoolchildren. F Pediatr 2014;165(1):104-9.

[22] Johannsson E, Arngrimsson SA, Thorsdottir I, et al. Tracking of overweight from early childhood to adolescence in cohorts born 1988 and 1994: overweight in a high birth weight population. Int $\mathcal{F}$ Obes 2006;30(8):1265-71.

[23] Poortvliet E, Yngve A, Ekelund U, et al. The European youth heart survey (EYHS): an international study that addresses the multi-dimensional issues of CVD risk factors. Forum Nutr 2003;56:254-6.

[24] Magnusson KT, Hrafnkelsson H, Sigurgeirsson I, et al. Limited effects of a 2-year school-based physical activity intervention on body composition and cardiorespiratory fitness in 7-year-old children. Health Educ Res 2012;27(3):484-94.

[25] Skúlason S, Gunnarsson F and Einarsdóttir E. Skýrsla um samræmd próf í 4. bekk árið 2003 [Report on standardized testing in $4^{\text {th }}$ grade 2003]. Contract no. 1, 2004. Reykjavík: Námsmatsstofnun.

[26] Skúlason S and Gunnarsson K. Skýrsla um samræmd próf i 4. bekk 2008. Report no. 5, 2008. Reykjavík: Menntamálastofnun.

[27] Tanner JM. Fallacy of per-weight and per-surface area standards, and their relation to spurious correlation. $\mathcal{F} \mathrm{Appl}$ Physiol 1949;2(1):1-15.

[28] Welsman JR and Armstrong N. Statistical techniques for interpreting body size-related exercise performance during growth. Pediatr Exerc Sci 2000;12:112-27.

[29] Moore SA, McKay HA, Macdonald H, et al. Enhancing a somatic maturity prediction model. Med Sci Sports Exerc 2015;47(8):1755-64.

[30] Katzmarzyk PT, Malina RM and Beunen GP. The contribution of biological maturation to the strength and motor fitness of children. Ann Hum Biol 1997;24(6): 493-505.

[31] Sigfusdottir ID, Kristjansson AL and Allegrante JP. Health behaviour and academic achievement in Icelandic school children. Health Educ Res 2007;22(1):70-80.

[32] Grissom JB. Age and achievement. Educ Policy Anal Arch 2004;12(49), http://epaa.asu.edu/epaa/v12n49/ (accessed 10 October 2016).

[33] Kim H-Y. Statistical notes for clinical researchers: assessing normal distribution (2) using skewness and kurtosis. Restor Dent Endod 2013;38(1):52-4.

[34] Cohen J. Preface to the revised edition. In: Cohen J (ed.) Statistical power analysis for the behavioral sciences. Revised ed. New York: Academic Press, 1977, pp. xi-xii.

[35] Rees DI and Sabia JJ. Sports participation and academic performance: evidence from the National Longitudinal Study of Adolescent Health. Econ Educ Rev 2010;29(5):751-9.

[36] Davis CL, Tomporowski PD, McDowell JE, et al. Exercise improves executive function and achievement and alters brain activation in overweight children: a randomized, controlled trial. Health Psychol 2011;30(1):91-8.

[37] Coe DP, Pivarnik JM, Womack CJ, et al. Effect of physical education and activity levels on academic achievement in children. Med Sci Sports Exerc 2006;38(8):1515-19.

[38] Shephard RJ. Habitual physical activity and academic performance. Nutr Rev 1996;54(4):5.

[39] Hillman CH, Pontifex MB, Motl RW, et al. From ERPs to academics. Dev Cogn Neurosci 2012;2(Suppl 1):S90-8.

[40] Fedewa AL and Ahn S. The effects of physical activity and physical fitness on children's achievement and cognitive outcomes: a meta-analysis. Res $Q$ Exerc Sport 2011;82(3):521-35.

[41] Martin A, Saunders DH, Shenkin SD, et al. Lifestyle intervention for improving school achievement in overweight or 
obese children and adolescents. Cochrane Database Syst Rev 2014;3:Cd009728.

[42] Kao SC, Westfall DR, Parks AC, et al. Muscular and aerobic fitness, working memory, and academic achievement in children. Med Sci Sports Exerc 2016;49(3):500-508.

[43] Kantomaa MT, Stamatakis E, Kankaanpää A, et al. Physical activity and obesity mediate the association between childhood motor function and adolescents' academic achievement. Proc Natl Acad Sci USA 2013;110:1917-22.

[44] Kamijo K, Khan NA, Pontifex MB, et al. The relation of adiposity to cognitive control and scholastic achievement in preadolescent children. Obesity (Silver Spring) 2012;20(12):2406-11.

[45] Mullender-Wijnsma MJ, Hartman E, de Greeff JW, et al. Physically active math and language lessons improve academic achievement: a cluster randomized controlled trial. Pediatrics 2016;137(3):1-11.

[46] Adamo KB, Prince SA, Tricco AC, et al. A comparison of indirect versus direct measures for assessing physical activity in the pediatric population: a systematic review. Int $\mathcal{f}$ Pediatr Obes 2009;4(1):2-27.

[47] Ekelund U, Tomkinson G and Armstrong N. What proportion of youth are physically active? Measurement issues, levels and recent time trends. Br $\mathcal{F}$ of Sports Med 2011; 45(11):859-65.

[48] McNaughten D and Gabbard C. Physical exertion and immediate mental performance of sixth-grade children. Percept Mot Skills 1993;77(3, Pt 2):1155-9.

[49] Bradley J, Keane F and Crawford S. School sport and academic achievement. $\mathcal{F}$ Sch Health 2013;83(1):8-13.

[50] Kantomaa MT, Purtsi J, Taanila AM, et al. Suspected motor problems and low preference for active play in childhood are associated with physical inactivity and low fitness in adolescence. PLoS One 2011;6(1):e14554.

[51] Cole TJ, Bellizzi MC, Flegal KM, Dietz WH. Establishing a standard definition for child overweight and obesity worldwide: international survey. BMF 2000;320(7244): $1240-1243$. 